\title{
RESPONSIBILITY ATTRIBUTION PROBLEMS IN COMPANIES: COULD AN ARTIFICIAL MORAL ADVISOR SOLVE THIS?
}

\author{
Radu USZKAI ${ }^{a *}$, Cristina VOINEA ${ }^{b}$, Toni GIBEA $^{c}$ \\ ${ }_{a, b, c}$ Bucharest University of Economic Studies, Romania
}

\begin{abstract}
The main claim of our paper is that managers should not outsource moral decision-making to Artificial Moral Advisors (AMAs) and that such devices should not be used as a way of offloading moral responsibility for business decisions. In other words, in the wake of the rise of Artificial Intelligence advisors, Chief Ethics Officers or business ethics consultants still have an integral role to play. In the first part of our paper we provide a brief overview of various examples of unethical behavior in business, followed by some hypotheses regarding why unethical behavior seems to be inescapable. We then proceed to present how AMAs could be used for the purpose of moral enhancement and analyze whether moral decisions could be outsourced towards them. Our main argument is that such a task is doomed to fail since AMAs are not responsible for their decisions/actions. We conclude by providing a positive agenda for the use of AI in the field of business ethics, by fleshing out how AMAs could be used as moral enablers.
\end{abstract}

KEYWORDS: Artificial Intelligence, Artificial Moral Advisor, business ethics, moral data, moral responsibility.

\section{DOI: 10.24818/IMC/2021/05.12}

\section{INTRODUCTION}

Corporations have a profound impact on the world. Undoubtedly, corporations can be said to be legal agents, a status that also confers them legal rights and obligations (Frost, 2016). But the question of whether corporations are or are not moral agents is still undecided (Rönnegard, 2013). Despite this, it is hard to contest the fact that corporate decisions have important ethical implications, touching on the well-being and integrity of both immediate stockholder and other stakeholders, such as the environment and even future generations. The bearing that companies have on a plurality of entities generates ethical obligations that sometimes clash with economic and strategic choices that must be pursued in order to advance companies' raison d'etre, which is the maximization of profits. But unlike laws and regulations, which are enforced by authorities, the adoption and respect of ethical obligations is voluntary, having no enforcement mechanisms to stand behind them besides agents' moral conscience.

A whole lot of unethical corporate behaviors have been in the public's eye ever since corporations came into being, but it seems that todays' corporate agents are not very keen to learn from history (Pendse, 2012). Unfortunately, corporate scandals - which became case studies in business ethics have implications not only on a financial level, but sometimes they directly harm the environment, citizens, consumers and all sorts of different stakeholders. In what follows, we will briefly go through some of the most famous cases of corporate misbehavior and their damaging consequences, in order to show that unethical behavior has been and continues to be a reality in the business world. Probably one of the most famous environmental catastrophes, the BP Deepwater Horizon oil spill,

\footnotetext{
* Corresponding author. E-mail address: radu.uszkai@man.ase.ro
} 
is a paradigmatic example of unethical corporate behavior that needs no further introduction. The effects of one of the largest oil spills in history, happening in 2010, still has damaging effects on the wildlife and ecosystem not only in the Gulf of Mexico, but also in surrounding areas (Meiners, 2020). More recently, in 2015, the Volkswagen emission scandal showed that the company willingly cheated on the air pollution tests and presented some of their cars as "environmentallyfriendly" when, in fact, they were polluting the environment just as much, and in some cases even more, than other cars which were not branded as "green" (Bovens, 2016). Volkswagen cheated not only its customers who were interested in buying cars that are less damaging to the environment, but also public authorities. But unethical corporate behaviors affect not only the environment, thus harming the well-being of current and future generations, they can also willingly and directly harm consumers' health and, sometimes, they even endanger their lives. One famous example is Nestlé, which ever since the 70s has been the protagonist of a worldwide scandal, being accused of aggressively promoting and hooking mothers in the developing countries on infant formula, by discouraging breastfeeding. This aggressive marketing behavior is said to have resulted in health problems and even deaths of babies that were fed with the Nestlé formula (Boyd, 2012). To this day, the boycott of the company is still ongoing, while the International Baby Food Action Network (IBFAN) is actively monitoring Nestlé's business and marketing practices. The list of unethical corporate behavior could probably go on indefinitely, with each industry sector having its famous "evildoer". More recently, technology companies have been in the public eye, either for the way they treat their employees, for their environmental impact or simply for not having done enough to stop the spread of mis- and disinformation online.

\section{WHY IS MORALITY SO DIFFICULT IN THE BUSINESS WORLD?}

Unethical behavior damages companies' reputation and image, which, in turn, takes a toll on employee's morale. Moreover, these scandals damage consumers' trust in business but also in the regulatory powers of states, by promoting a toxic climate of mistrust and suspicion. As a result, companies have put mechanisms in place - ethical committees, ethical codes of conduct, ethical trainings and so on - to prevent ethical misbehavior and malfeasance. Despite this, recurring scandals only show what we are currently doing to make the business environment more ethical is not enough.

Despite all the regulatory and self-regulatory measures taken up by companies in order to prevent the apparition and spread of corporate misbehaviors, unethical decisions and practices still abound in the corporate world. Why is it then so difficult for companies to internalize and put into practice ethical values and principles?

First, as in any complex organization or decision-making structure, it is difficult to pin-point the one agent who is responsible for a bad outcome. Despite the differences regarding what moral responsibility is and how it should be ascribed, most moral theories accept that one can be held morally responsible for certain outcomes insofar as they have caused them voluntarily (freedom of action and causation conditions), act with knowledge (knowledge condition) and act after a process of deliberation (Constantinescu et al., 2021a). But in big organizations such as companies, it is oftentimes difficult to trace responsibility back to a single person, as decisions pass to a wide range of offices and personnel, none of which have complete information relevant to that decision (Thompson, 1980). This difficulty in responsibility ascription is called 'the problem of many hands' (Van de Poel et al., 2012). Thomson, who conceptualized and named for the first time this problem in relation to public officials, describes it as such: "Because many different officials contribute in many ways to decisions and policies of government, it is difficult even in principle to identify who is morally responsible for political outcomes" (Thomson 1980, p. 905). The many hands problem arises in any complex organization, thus in most organizations in the business world as well, 
because it is difficult to apply traditional conditions for responsibility - such as intent, knowledge and freedom of action - to any one individual, as they are distributed over many individuals which do not, by themselves, satisfy all three conditions. In other words, moral responsibility ascription is obscured in complex organizations, and this is one of the main reasons for unethical corporate behavior. Also, employees know that they cannot be held, by themselves, responsible for an action. The worry is that the unclear responsibility attribution within a company actually stimulates employees to act in a carless and unethical manner without thinking through all of the possible consequences of their actions.

Secondly, what is specific to the business environment is competition. The traditional economic approach to competition sees it as a fundamental element in any market economy, as it "ensures efficient management of resources and incites innovation and thus has a positive impact on the community" (Quairel-Lanoizelée, 2011). While competition does not exclude cooperation, it nonetheless adds additional pressures on corporate decision-making processes, pushing companies to act quickly, on the spur of the moment, without taking the time to think through all of the possible consequences of their actions. But competition could also theoretically drive businesses to act more ethically. We can imagine a world where consumers demand and only consume truly sustainable products; in order for companies to be successful, they would have to innovate and only develop environmentally-friendly products and services in order to remain competitive. Unfortunately, we do not live in that world and todays' consumers are more interested in buying cheaper products in order to save more money, which means that companies are incentivized to lower production costs. Also, competition amongst multinationals pushes them to adopt externalization processes, which also include outsourcing to countries where regulations regarding workers' treatment or the environment are more permissive.

These are just some of the reasons that push companies into behaving unethically. The fact that many people are involved in decision-making processes, coupled with the fact that none of the agents involved have all the relevant information regarding a certain decision, leads to a situation where it is difficult to attribute responsibility for an outcome to an agent or a group of agents. Also, competition pushes companies into acting quickly in order to safeguard their advantages, which oftentimes means that the ethical implications of the decision-making processes will not be thought through.

On top of these two reasons, there might be something which is even more daunting when it comes to our inability (not only as managers, but as human beings in general) to (always) act in a morally appropriate manner. Firstly, as recurring research from moral and behavioral psychology (Haidt, 2012; Savulescu \& Maslen, 2015; Sunstein, 2005) has pointed out, human beings suffer from a wide range of psychological shortcomings which - at least in some cases - hinder our moral decision-making process. Take, for example, some of the biases which are extremely relevant for business contexts like in-group bias or our temptation to discount the future. Were we to look at the former, it becomes clearer why managerial decisions tend to be in favor of the welfare of their organization, regardless of other (sometimes) more relevant ethical underpinnings at play. The same goes for the former: if managers see their role as decision makers with the goal of maximizing profits on the short run, then future welfare for a lot of the stakeholders involved will be discounted. Furthermore, as Giubilini \& Savulescu (2018) point out, there is something inherently problematic in the way in which human beings (managers included, obviously) are equipped to tackle moral problems. If they were to face an ethical dilemma, managers are in deep water because they are unable to be optimal information processors. As any other individual, a manager is unable to cast aside her intuitions and moral emotions when she analyzes relevant information of the case at hand, to always escape her own cognitive limitations, and to grapple with all the relevant information that she would need in order for her decision to be a rational and moral one. This, we would like to add, happens regardless of how much moral 'noise' (Kahneman, Sibony \& Sunstein, 2021) there might be in the context in which she acts. Furthermore, even if human beings were to be excellent at 
information processing, there would still be two additional problems: we (at least sometimes) fail to act along the lines of the principles that we say we share, and various psychological shortcomings like akrasia can kick any when we are on the verge of deciding how to act in a given context.

\section{SHOULD ETHICAL DECISION-MAKING BE OUTSOURCED TO ARTIFICIAL MORAL ADVISORS?}

Throughout history, and especially ever since the Industrial Revolution, we have outsourced a wide variety of physical and cognitive tasks to technology, with some notable success. In recent years, ever since the advent of Artificial Intelligence, the debate regarding how many more tasks could be outsourced from humans to intelligent machines is a really heated one, with various projections being made regarding the increase in productivity, but also the looming specter of technological unemployment for both blue and white collar workers in the wake of automation (Susskind \& Susskind, 2015; Susskind 2020), with individuals involved in Human Resource Management (Tambe, Cappelli \& Yakubovich, 2019) or auditing services (Munoko, Brown-Liburd \& Vasarhelyi, 2020) entering recently on the radar. Could compliance and ethics officers, with their diverse attributions and skills (Krenitsky, 2020), or business ethics consultants be next?

While the debate regarding human and moral enhancement is already deeply entrenched in the current scholarly literature (Clarke et al., 2016), 'AIenhancement' (Lara \& Deckers, 2020) is an emerging topic of discussion, building on proposals from the past couple of years which were first formulated in a coherent manner by Savulescu \& Maslen (2015) and Giubilini \& Savulescu (2018). Such Artificial Moral Advisors, as they have been called, tap into an already existing usage of Artificial Intelligence for various types of assistance. Some have become an integral part of our day to day life. For example, we regularly tend to use Google Maps in order to navigate our surroundings. Others are more relevant for certain niches. That is the case of increasingly popular AI-powered financial assistant apps like MintZip or Olivia.ai.

Either as apps that managers could have installed on their smartphones, or embodied as humanoid robots in the near future, Artificial Moral Advisors are, first and foremost, pieces of software which would use Artificial Intelligence in order to provide users with moral advice. They would be able to do this by closely monitoring the environment of the user and by providing her with a wide variety of moral principles and values relevant for a particular dilemma which she faces. Those moral principles and values could be integrated either within a top-down approach (designers and software developers could imbue the AMA with explicitly Kantian/utilitarian/virtue ethics principles for action), or by a bottom-up one, which would make use of machine learning in order to generate the relevant moral software for the user (for instance, the user might be asked to answer a couple of questions in order for the AMA to correctly pinpoint her moral weltanschauung).

In order to understand how such an AMA would work in a business environment, we propose the following thought experiment adapted from Sparrow (2021). Imagine you are the manager of a company that recently lost its Chief Ethics Officer. You have instructed your HR department to start working on finding a replacement for your former colleague, when your company encounters a flurry of ethical dilemmas (you can take your pick here, from cases involving harassment and discrimination, to difficulties in ascribing the most relevant stakeholder in a potential CSR campaign). As the process of hiring someone in such an important role can be long and complicated, a friend of yours who works for a software company has the solution: you should install on your smartphone the best Artificial Moral Advisor on the market, an app that uses state of the art AI in order to provide its users with advice tailor-made for their needs. The AMA is trained by developers with data from all the relevant academic databases in both philosophy and ethics which were curated by top moral experts. Moreover, such an app would also have a 'Socratic' component (Lara \& Deckers, 2020): after installing it on your phone, you will not only be able to provide as an input your own moral preferences, but the app will also ask you a couple of relevant 
questions in the process in order to weed out the nefarious impact which biases might have on your moral identity. By monitoring the environment of the dilemma at hand and by allowing all the relevant stakeholders to introduce relevant information for the decision-making process, the AMA provides you a personalized advice which would take into account your own moral criteria and all the relevant normative frameworks provided by the best moral experts from academia which would work as filters aimed at making sure that your decision is correct. As a manager, should you use an AMA? The short answer is yes, but it depends on how you would do it (more on this really soon). Should you exclusively use an AMA instead of hiring a new Chief Ethics Officer, thus relying exclusively on it and outsourcing all your ethical decisions to such an app (or to an android embodied version of it, if you care to make things more interesting)? No, not really.

\subsection{AMAs and moral responsibility}

While we find the prospect of using such AMAs as being definitely entertaining, there are some reasons to at least welcome them with a pinch of salt. More than two decades ago, some scholars have been skeptical about using AI for ethical decision - making, brandishing this project with the label of 'science fiction', as nothing more than a figment of our imagination. As Khalil (1993) argued, such expert moral systems would either lack certain relevant features (human-like intelligence, moral emotions), or have certain fatal flaws (intentional/accidental bias incorporated in the software/data).

More recently, and in the wake of visible progress being made in the field of AI research, the worries have diversified. For Sparrow, not only outsourcing ethical decision-making to an AMA, but even using it in order to help you decide what to do when you face a moral dilemma as a manager is nothing more than a "shallow simulacrum of ethics" (2021, p.1). Other moral philosophers, like Shannon Vallor, see a different type of threat. Using such artificial advisors, for both non-moral (e.g. financial) and moral purposes would lead to 'deskilling' (2015). Instead of helping us, such tools would end up being morally 'debilitating' (2016). An in depth discussion of these worries would extend beyond the scope of this paper, as our claim is that the crux of the problem lies somewhere else: moral outsourcing in business organizations to an AMA rests upon the issue of whether such expert AI moral systems could be held morally responsible for their advice/decisions.

Our argument follows closely Constantinescu et al. (2021a) discussion of the four relevant conditions for ascribing moral responsibility to an action (causation, freedom, knowledge and deliberation) and their subsequent Moral Responsibility Test.

First of all, if managers were to outsource moral decision-making to an AMA, could we say that the AMA causes any outcome as a result of its own initiated action or inaction? The answer is quite trivial: it does not, since it is the manager who decides to install and use it (and act based on the advice provided). Furthermore, if a human Chief Ethics Officer can be a first principle of an action (for example the decision to punish someone for blatantly disregarding the company's code of conduct), an AMA could only play an instrumental role, being nothing more than a secondary cause - even taking into account the possibility that the AMA could nudge a manager into taking a decision she otherwise would have not contemplated.

If the AMA does not meet the causation condition, then it cannot meet the freedom condition as well. Even if they could act physically in the world (again, AMAs could be embodied in android bodies), they are still conditioned and coerced by its design: by the initial data set provided by the programmers, by the input data from human users and by the moral preferences of the manager. If something (or someone) cannot choose their own rules of action, then that something lacks freedom in a morally relevant way. While we would not set up such a high bar for other types of advisors (i.e. we do not actually want financial advisors or Google Maps to be autonomous), things are quite different when the stakes are normative. The last two conditions (knowledge and deliberation), are also closely intertwined. Can an AMA be said to actually be morally knowledgeable of the relevant 
information needed to take a decision? Not really, since it relies on the information which managers or other users would feed it (both empirical - factual - or more abstract - principles and values). Even if we were to imagine an AMA which would have access to information without the users' mediation, it would face something that, at this day and age, seems insurmountable: it could not be able to always distinguish between the relevant and irrelevant contextual moral knowledge since it lacks personal experience and a personal moral history. If the AMA lacks a moral personality, then it cannot be said that it could morally deliberate. While AI systems could process huge amounts of data, moral deliberation cannot be reduced to an impersonal moral algorithm. Practical wisdom, as Aristotle would put it, is needed for being a moral deliberator, and that is something that, at this point in time at least, an AI could not possess (Constatinescu et al. 2021b).

If moral responsibility still remains a 'human affair' and AMAs are still far from being something like Lieutenant Commander Data from Star Trek, then moral outsourcing and responsibility offloading in companies is doomed to fail. This does not mean that AMAs do not have a role to play in business, quite the contrary (Khalil, 1993). If we were to take this project seriously, and if they were to accurately play their role, then they should be seen as moral enablers, with the purpose of mitigating the impact of some of our moral, cognitive and neuropsychological shortcomings.

\section{CONCLUSIONS: ARTIFICIAL INTELLIGENCE AND MORAL ENABLING}

A computer is capable of operating based on a complex set of formal rules at incredible speeds, way beyond human capabilities. To function in good parameters, computers need well defined rules as inputs about the real world. In general, humans form and define the rules for machines, a method which is known in AI as the knowledge-based approach. Ironically, as humans, we can perform simple tasks intuitively, like recognizing objects or understanding the meaning of a sentence, but we are unable to define a complex set of rules for these tasks, therefore without a set of well-defined rules a computer is unable to perform these simple tasks. Computer scientists designed algorithms capable of recognizing and extracting abstract rules on their own, based on certain features and patterns from real-world datasets. This process is known as 'machine learning' in AI and the role of the data for training the algorithm is paramount (Goodfellow et al., 2016). In the following section we are going to concentrate on the former approach in AI and speculate in how many ways it can morally enable managers.

Today we are using trained algorithms to automatically add emails into spam, to recognize objects from images, translate texts and perform other tasks used in multiple applications. In the field of ethics, the Allen Institute for AI designed an application called the 'Delphi AI', where a machine could ponder moral questions and offer moral advice. As we argued in the previous section, we believe that an AI should not oversee, but enable the CEOs and the managers in the process of moral decision-making. How exactly it morally enables managers depends upon what kind of datasets are used. Based on what kind of data experimental moral philosophers gather (Alfano et al., 2018) we can distinguish between at least three distinct types of datasets: (i) universal moral data; (ii) professional moral data; (iii) local or specific moral data. At this point, we will not discuss the content of the moral data, how it is normatively relevant or how it is different from other kinds of data, like medical or financial data. We are assuming that the data gathered by the experimental moral philosophers could train algorithms and we categorized it into one of the above-mentioned three sets.

An algorithm trained with all the available moral data (a universal moral dataset) offers us a general moral outlook and it could be extremely useful for managers especially when they want to avoid a morally controversial decision. For example, they could immediately avoid getting involved in a heated debate about abortion, gender issues or euthanasia, since they could see how polarized the society is over certain moral issues. They can also avoid offending cultural values or socially accepted norms if their company operates in a country with a different cultural background from 
their own. The biggest disadvantage is that the data could also mislead the CEOs and the managers since avoiding or complying with cultural and social norms might indulge unethical behaviors, such as various kinds of discriminations. An AI could also signal to the managers that they are facing a dilemma. For example, they would have to choose between doing what is known to be right in most cultures and societies and doing what is profitable in a particular case. If they choose the profitable option, then they should also take the responsibility and explain their decisions, especially since the AI would offer a reliable general moral outlook.

In the case of professional moral data, companies could easily adopt and make decisions in accordance with a well-established professional practice. In this instance, it is important that the data is composed from answers of professionals from specific fields of work (accounting, marketing, human resources, sales, banking, healthcare and so forth). This way, all the companies which operate in a certain business sector could adopt a universal rulebook based on the characteristics of their own profession, beyond cultural or social interferences. The algorithm could help professionals better understand and recognize the professional ethical dilemmas specific in their own line of work and prepare them to cope with the challenges and the consequences of their own decision. There are at least two drawbacks to such an algorithm. Technically, it is difficult to dissociate between professional specific judgments and non-professional ones. Not all the moral data we gather from someone who works in accounting, for example, would be specific only to that field. Other variables might come into play which are hard to control, like gender, age, culture, level, type of education, etc. The second challenge rests upon the fact that professional ethical issues and cases are not easily judged out of their context. Different countries have different regulations and even mentalities regarding what professionals ought to do. For example, in medical practices the institution of informed consent is interpreted in different ways by patients (Halkoaho et al., 2016). This idea is in general well supported in the emerging field of cross-cultural studies of professionals.

An algorithm trained with data from one company, a branch or a department could detect the moral judgments of the employees (local or specific data). You can analyze and compare all these judgments, identify the issues, and address them. For example, if you realize that all the employees from a certain branch believe that they should take full responsibility for their mistakes and try to fix them by themselves, then you could try and encourage this attitude or discourage it, depending on what kind of organizational culture fits the company. Just to give another example, if the algorithm helps you realize the employees believe that the responsibility is in general shared in the company for both bad and good outcomes you could implement a program to endorse individual responsibility and give proper incentives. There are at least two arguments against these third kinds of algorithms. First, it would be hard to index and structure the data. From the beginning, the amount of data is way more limited and probably less likely that an algorithm could easily identify strong patterns or relations in relatively small quantities of data. Second, it is hard to gather honest responses from the employees. Most of them will probably see the process of collecting data on moral topics as an inquiry from the company and will prefer to say what is in general expected to say on these moral topics. Although we can identify arguments both for and against algorithms trained with all these three kinds of datasets, it is exciting to examine in how many ways AI could enable the managers to make moral decisions.

\section{ACKNOWLEDGMENT}

Cristina Voinea and Radu Uszkai's work was supported by a grant of the Romanian Ministry of Education and Research, CNCS-UEFISCDI, project number PN-III-P1-1.1-TE-2019-1765, within PNCDIIII, awarded for the research project Collective moral responsibility: from organizations to artificial systems. Re-assessing the Aristotelian framework, implemented within CCEA \& ICUB, University of Bucharest (2021-2022). 
Toni Gibea's contribution was supported by a postdoctoral grant from the Romanian Young Academy funded by Stiftung Mercator and hosted by the University of Bucharest (2021-2023).

\section{REFERENCES}

Alfano, M., Loeb, D. \& Plakias, A. (2018). Experimental moral philosophy. The Stanford Encyclopedia of Philosophy. Retrieved November 5, 2021, from https://plato.stanford.edu/entries/experimental-moral/.

Bovens, L. (2016). The Ethics of Dieselgate. Midwest Studies in Philosophy, 40, 262-83.

Boyd, C. (2012). The Nestlé Infant Formula Controversy and a Strange Web of Subsequent Business Scandals. Journal of Business Ethics, 106(3), 283-93.

Clarke, S., Savulescu, J., Coady, C. A. J., Giubilini, A. \& Sanyal, S. (2016). The Ethics of Human Enhancement. Understanding the Debate. Oxford: Oxford University Press.

Constantinescu, M., Vică, C., Uszkai, R. \& Voinea, C. (2021a). Blame it on the AI? On the moral responsibility of Artificial Moral Advisors. Retrieved November 5, 2021, from www.researchgate.net/profile/Mihaela-Constantinescu-5/publication352904941_Blame_it _on_the_AI_On_the_moral_responsibility_of_Artificial_Moral_Advisors/links 61727a55435dab3b7594c274/Blame-it-on-the-AI-On-the-moral-responsibility-of-ArtificialMoral-Advisors.pdf

Constantinescu, M., Voinea, C., Uszkai, R. \& Vică, C. (2021b). Understanding responsibility in Responsible AI. Dianoetic virtues and the hard problem of context. Ethics and Information Technology. https://doi.org/10.1007/s10676-021-09616-9.

Françoise, Q.-L. (2011). Are Competition and Corporate Social Responsibility Compatible? The Myth of Sustainable Competitive Advantage. Society and Business Review, 6(1), 77-98.

Frost, N. (2016). Transnational Corporations as Agents of Legal Change: The Role of Corporate Social Responsibility. Cambridge International Law Journal, 5(3), 502-28.

Giubilini, A. \& Savulescu, J. (2018). The Artificial Moral Advisor. The "Ideal Observer" Meets Artificial Intelligence. Philosophy \& Technology, 31, $169-188$.

Goodfellow, I., Bengio, Y. \& Courville, A. (2016). Deep Learning. Cambridge (MA): MIT Press.

Haidt, J. (2012). The righteous mind: Why good people are divided by politics and religion. New York: Pantheon/Random House.

Halkoaho, A., Pietilä, A.-M., Ebbesen, M., Karki, S. \& Kangasniemi, M. (2016). Cultural aspects related to informed consent in health research: A systematic review. Nursing Ethics, 23(6), 698-712.

Kahneman, D., Sibony, O. \& Sunstein, C. R. (2021). Noise: A Flaw in Human Judgment. London: William Collins.

Khalil, O. E. M. (1993). Artificial decision-making and artificial ethics: A management concern. Journal of Business Ethics, 12, 313-321.

Krenitsky, J. (2020). The compliance and ethics officer of the future: What skills are necessary?. Journal of Financial Compliance, 3(3), 255-261.

Lara, F. \& Deckers, J. (2020). Artificial Intelligence as a Socratic Assistant for Moral Enhancement. Neuroethics, 13, 279-287.

Meiners, J. (2020, April 17). Ten Years Later, BP Oil Spill Continues to Harm WildlifeEspecially Dolphins. National Geographic. Retrieved November 5, 2021, from https://www.nationalgeographic.com/animals/article/how-is-wildlife-doing-now--ten-yearsafter-the-deepwater-horizon.

Munoko, I., Brown-Liburd, H. L. \& Vasarhelyi, M. (2020). The Ethical Implications of Using Artificial Intelligence in Auditing. Journal of Business Ethics, 167, 209-234.

Pendse, S. (2012). Ethical Hazards: A Motive, Means, and Opportunity Approach to Curbing Corporate Unethical Behavior. Journal of Business Ethics, 107(3), 265-79. 
Rönnegard, D. (2013). How Autonomy Alone Debunks Corporate Moral Agency. Business and Professional Ethics Journal, 32(1/2), 77-107.

Savulescu, J. \& Maslen, H. (2015). Moral Enhancement and Artificial Intelligence: Moral AI?. In J.Romportl, E. Zackova, \& J. Kelemen (Eds.), Beyond artificial intelligence: The Disappearing human-Machine Divide (pp. 79-95). New York: Springer.

Sparrow, R. (2021). Why machines cannot be moral. AI \& Society, https://doi.org/10.1007/s00146020-01132-6

Sunstein, C. R. (2005). Moral heuristics. Behavioral Brain Sciences, 28, 531-573.

Susskind, D. (2020). A world without work: Technology, automation and how we should respond. London: Penguin.

Susskind, R. \& Susskind, D. (2015). The future of the professions: How technology will transform the work of human experts. Oxford: Oxford University Press.

Tambe, P., Cappelli, P. \& Yakubovich, V. (2019). Artificial Intelligence in Human Resources Management: Challenges and a Path Forward. California Management Review, 61(4), 1-28.

Thompson, D. F. (1980). Moral Responsibility of Public Officials: The Problem of Many Hands. American Political Science Review, 74(4): 905-16.

Vallor, S. (2015). Moral Deskilling and Upskilling in a New Machine Age: Reflections on the Ambiguous Future of Character. Philosophy \& Technology, 28, 107-124.

Vallor, S. (2016). Technology and the Virtues: A Philosophical Guide to a Future Worth Wanting. Oxford: Oxford University Press.

Van de Poel, I., Fahlquist, J. N., Doorn N., Zwart, S. \& Royakkers, L. (2012). The Problem of Many Hands: Climate Change as an Example. Science and Engineering Ethics, 18(1), 49-67. 